\title{
A representatividade nos conselhos gestores: fundamentos e elementos constitutivos
}

\section{The representation in management councils: theoretical foundations and components}

\author{
Carla Buhrer Salles Rosa* \\ Danuta E. Cantoia Luiz ${ }^{* *}$
}

\begin{abstract}
Resumo: O presente artigo tem como objetivo apresentar uma sistematização sobre um dos elementos que compõem e desafiam a materialização de processos democráticos de gestão social no Brasil contemporâneo: a representatividade dos segmentos sociais no interior de espaços institucionalizados de participação social (conselhos gestores de políticas públicas). Considerados como novas instâncias de intermediação pública, provocam alterações no âmbito do governo representativo, a partir da participação direta de segmentos da sociedade civil nesses espaços. Mesclando mecanismos de democracia direta e democracia representativa, reordenam a lógica do poder tradicional. A implantação dos conselhos gestores de políticas públicas no Brasil coloca no cenário político cem mil conselheiros que podem ser vistos como sujeitos políticos com possibilidades de contribuir com processos democráticos mais amplos, porém há que se preencher as lacunas existentes em tais espaços. Uma dessas lacunas é a efetiva representatividade.
\end{abstract}

Palavras-chave: Representatividade. Sujeitos representativos.

\begin{abstract}
This article aims to present a systematization of one of the elements that constitute and also challenge the materialization of democratic processes of social management in contemporary Brazil: the representativeness of the social segments within institutional spaces for social participation (public policy management councils). Considered as new instances of public intermediation, they cause changes in the representative government from the direct participation of civil society groups in these spaces, merging mechanisms of direct democracy and representative democracy, to reorder the logic of traditional power. The implementation of public policy management councils in Brazil puts on the political scenario one hundred thousand of advisers who can be seen as political actors with opportunities to contribute to wider democratic processes. However, the gaps in these areas still have to be filled, and one of them is the effective representativeness.
\end{abstract}

Keywords: Representational. Representational subjects.

Recebido em: 17/06/2011. Aceito em: 12/05/2012.

\footnotetext{
* Mestre em Ciências Sociais Aplicadas e graduada em Serviço Social pela Universidade Estadual de Ponta Grossa (UEPG). Assistente social da Prefeitura Municipal de Ponta Grossa. Ponta Grossa, Paraná, Brasil. E-mail: carlajb@interponta.com.br

** Doutora em Serviço Social pela Pontifícia Universidade Católica de São Paulo (PUC-SP). Mestre em Serviço Social pela PUC-SP. Graduada em Serviço Social pela Universidade Estadual de Ponta Grossa (UEPG). Professora Associada do Departamento de Serviço Social da UEPG. Ponta Grossa, Paraná, Brasil. E-mail: danutaluiz88@gmail.com
} 


\section{Introdução}

Este texto tem por objetivo refletir sobre o significado da categoria "representatividade" dos segmentos da sociedade civil nos espaços de participação social, por meio de revisão bibliográfica. Integra os estudos realizados para a dissertação de Mestrado em Ciências Sociais Aplicadas. A partir de autores clássicos e contemporâneos, este trabalho conceitua representação política e seus desdobramentos nas formas atuais de democracia e, sobretudo, como essa representação se dá nos atuais espaços de participação.

No Brasil, vivemos hoje a pluralização dos espaços de participação na gestão das políticas públicas. Com essa pluralização, também ocorre a pluralização dos sujeitos representativos envolvidos no processo, levando as expectativas de comunidades, grupos e organizações para o interior de debates públicos.

Os espaços de participação, institucionalizados a partir da Constituição Federal de 1988, possuem como um de seus objetivos que segmentos da sociedade civil tenham acesso ao poder, apresentando suas demandas, vocalizações, e participando das decisões que lhes dizem respeito na condição de integrantes de uma sociedade. Nesse âmbito, os representantes devem expressar os anseios dos representados, contribuindo para que tais espaços se tornem uma garantia para que os interesses gerais sejam efetivados, construindo uma alternativa aos mecanismos tradicionais e hegemônicos de representação política (votar e ser votado sob as determinações culturais e históricas do país).

A representação supõe regras para sua efetivação, as quais deverão ser amplamente compartilhadas para a autorização dos representantes e o controle pelos representados. Estas indicam uma tarefa importante para a efetivação e a legitimidade da representatividade como elementos que compõem o processo (em construção no Brasil) de democratização da gestão de políticas públicas.

Buscamos sistematizar alguns fundamentos e elementos constitutivos desse debate, no qual também é importante a discussão sobre "os sujeitos que participam destes espaços, uma vez que a densidade política destes espaços depende também da densidade política destes sujeitos." (DURIGUETTO, 2011).

\section{Representatividade: fundamentos e elementos constitutivos}

Para Bobbio, Matteucci e Pasquino (1998) o conceito de representação política, tanto em suas implicações teóricas como em suas traduções práticas, é sem dúvida um dos elementos-chave da história política moderna. Um significado para o termo "representação" seria: "substituir, agir no lugar de ou em nome de alguém ou alguma coisa; evocar simbolicamente alguém ou alguma coisa; personificar, [...] representar é possuir certas características que espelham ou evocam as dos sujeitos ou objetos representados" (BOBBIO; MATTEUCCI; PASQUINO, 1998, p. 1102). Ainda como tentativa de conceituar representação, apresentamos as seguintes colocações do dicionário de política:

O sentido da representação política está na possibilidade de controlar o poder político, atribuída a quem não pode exercer pessoalmente o poder. Assim, pode ser satisfeita a exigência fundamental que desde as primeiras e incertas origens fez surgir a instituição da representação, exigência expressa na Idade Média [...]. Com base em suas finalidades, poderíamos, portanto, definir a representação com um mecanismo político particular para a realização de uma relação de controle (regular) entre governados e governantes. (BOBBIO; MATTEUCCI; PASQUINO, 1998, p. 1102).

Bobbio (2000), quando se refere à democracia dos antigos e à democracia dos modernos, aponta que, por democracia, os antigos entendiam a democracia direta, e os modernos a democracia representativa. $O$ autor aponta duas diferenças entre essas formas de democracia, uma analítica e outra axiológica. Ambas estão extremamente conectadas e o "modo de avaliá-la, negativo ou positivo, depende do modo de entendê-la" (BOBBIO, 2000, p. 375).

Quando falamos em democracia, o que nos vem à mente? As eleições, cidadãos que exercem o direito ou o dever de eleger quem vai representá-los. Assim, "o voto, ao qual se costuma associar o relevante ato de uma democracia atual, é o voto não para decidir, mas sim para eleger quem deverá decidir." (BOBBIO, 2000, p. 372). 
O processo de democratização é descrito como a ampliação do direito de eleger os representantes e a extensão do processo eleitoral, ou seja, método democrático "é aquele acordo institucional para se chegar a decisões políticas em que os indivíduos adquirem o poder de decisão através de uma luta competitiva pelos votos da população" (SCHUMPETER, 1984, p. 336).

No período clássico, o espaço local onde se materializava a democracia era uma praça ou uma assembleia, na qual os cidadãos participavam do processo decisório, ou seja, a democracia direta $^{1}$ era a regra para decisões coletivas / políticas. Hoje, a eleição é a regra e a participação direta a exceção, enquanto antigamente ocorria o oposto. Essa alteração foi efeito da mudança das condições históricas, como a transição das cidades-estado para os grandes Estados territoriais. Bobbio (2000) aponta que isso não ocorreu somente pela alteração das condições históricas, mas também por efeito de uma concepção moral de mundo diferente. Ou seja, ampliou-se a concepção de mundo no sentido das relações entre indivíduos, grupos, comunidades, Estados, tendo como pano de fundo os valores democráticos modernos.

Rousseau, ao manifestar-se sobre a representação, coloca: "A ideia dos representantes é moderna; vem do governo feudal. [...] Nas antigas repúblicas, e inclusive nas monarquias, jamais o povo teve representantes, não se conhecia sequer este nome" (ROUSSEAU, 2002, p. 131).

$\mathrm{Na}$ inclusão de elementos da democracia direta, além da democracia representativa (da democracia dos antigos para a democracia moderna), desaparece a praça, "mas não a exigência de visibilidade do poder" (BOBBIO, 2000, p. 387). Esta passa a ser satisfeita de outra forma, com a publicidade das sessões do parlamento, por intermédio da imprensa e dos meios de comunicação de massa. Representar, então, "significa tornar visível [...] um ser invisível por meio de um ser que está presente publicamente" (SCHMITT, 1984, apud BOBBIO, 2000, p. 387).

\footnotetext{
1 O tipo de democracia presente no período clássico foi a democracia direta, com a participação dos cidadãos em espaços públicos para decisões coletivas/políticas. Porém, o limite desse período está na condição de cidadania, pois era cidadão o proprietário de terras que não precisava trabalhar (com tempo livre), o qual podia participar das assembleias e decisões coletivas.
}

A definição de democracia como via, como método, como conjunto de regras do jogo que estabelecem como devem ser tomadas as decisões coletivas, é relativamente nova. Essas regras do jogo são válidas para a regra de maioria, ${ }^{2}$ para a eleição daqueles aos quais é atribuído o poder de tomar decisões válidas para toda a coletividade. Indica quantos governam e não como governam

Segundo Vázquez (2001), a democracia pode ser entendida em dois sentidos:

[...] que não se excluem: como sistema ou regime de organização social em que o poder, a tomada de decisões, se acha submetido a certo controle da sociedade. Ou também como um caminho para chegar a esse poder ou conjunto de procedimentos para exercê-lo sob o controle da sociedade. (VÁZQUEZ, 2001, p. 83).

A partir dos apontamentos desse autor, entendemos que "representatividade", neste debate, pode ser vista como método, e para tanto supõe algumas regras do jogo, e a democracia é considerada como substância da vida social e política. Nessa perspectiva, Bobbio (2000, p.454) afirma que "o princípio de maioria é apenas um dos elementos para o bom funcionamento de um sistema democrático."

Compreendemos que para uma sociedade democrática não bastam as regras do jogo democrático, direitos de liberdade, ou ainda decisões da maioria, como propõe Bobbio (2000); é necessária a democratização de suas relações econômicas e sociais. Desse modo, democracia não é vista apenas como método ou forma institucional, mas sim como democracia substantiva, democracia que advém das massas, com vistas à superação das desigualdades para a edificação de um novo projeto societário.

Nesse debate, consideramos importantes alguns pontos trazidos à tona por Bobbio (2000), como: a interpretação econômica da democracia, que coloca a existência de um mercado político ao lado de um mercado econômico - no qual ocorre a relação entre os eleitores e os eleitos. Essa relação seria uma contínua troca entre dois

\footnotetext{
2 "Para Aristóteles, a democracia é o governo de muitos, uma vez que é o governo dos pobres, os quais são em geral a maioria da população, enquanto a oligarquia é o governo de poucos, uma vez que é o governo dos ricos, os quais são em geral uma minoria." (BOBBIO, 2000, p. 429).
} 
bens, o apoio (voto) por parte dos eleitores, e benefícios por parte dos eleitos. Porém, como enfatiza o autor, "faz parte dessa transformação do espaço político o fenômeno [...] da renovada importância da representação dos interesses." (BOBBIO, 2000, p. 457). Nesse sentido, interesse pode significar tanto uma situação objetiva, ou seja, uma coisa, um ato, um evento do qual se possa extrair uma vantagem ou um benefício, quanto um estado subjetivo, ou seja, uma disposição favorável em relação àquela coisa ou ato ou evento, conforme explicita Bobbio (2000).

A grande diferença que é necessário pontuar está na oposição entre os interesses parciais (de grupos particulares) e interesses gerais, pois um dos argumentos, elementos ou regras para o verdadeiro representante é a prioridade dos interesses gerais. Acreditamos, assim como Rousseau (2002), que a vontade geral é indestrutível e deve estar acima dos interesses particulares, como vemos:

Enquanto numerosos homens reunidos se consideram como um corpo único, sua vontade também é única e se relaciona com a comum conservação e o bem-estar geral. [...] a vontade geral é sempre constante, inalterável e pura; mas está subordinada a outras que a subjugam. Cada qual, destacando o próprio interesse do interesse comum, percebe que não os pode dividir completamente; mas parece-Ihe insignificante sua parte do mal público perto do bem exclusivo de que deseja apropriar-se. (ROUSSEAU, 2002, p. 142-144).

A democracia representativa tornou os partidos necessários, pois são eles, mediante o sistema eleitoral, que recebem dos eleitores a autorização para agir, a qual Bobbio (2000) percebe como a essência da representação política. Porém, os partidos se interpuseram entre o corpo eleitoral e o parlamento, ou entre o titular da soberania e quem deve de fato exercê-la e acabaram, assim, por despedaçar a relação direta entre eleitores e eleitos, tornando cada vez mais frágil a relação originária e característica do Estado representativo entre representante e representado. Nesse sentido, Bobbio se manifesta:

[...] no que se refere à relação entre partidos e eleitos, soberanos não são os deputados. Soberanos são os partidos, cuja diretriz política orienta, dirige e vincula o grupo parlamentar.
O termo "partidocracia" reflete esse estado de coisas [...] quem toma as decisões em última instância não são os representantes como mandatários livres dos eleitores, mas os partidos como mandantes imperativos dos chamados representantes [...] em oposição à representação dos interesses. (BOBBIO, 2000, p.470-471).

A representação política ${ }^{3}$ nas democracias contemporâneas sofreu transformações profundas nas últimas décadas do século $X X$, como apontam Lavalle, Houtzager e Castello (2006a). Essas transformações têm sua origem na perda pelos partidos políticos das preferências do eleitorado, as quais têm levado a representação política a ultrapassar as eleições e o legislativo como lócus da representação, enveredando para o controle social e outras formas de representação junto às funções do governo. Nesse sentido, a representação política deve ter como ideia central o aprofundamento da democracia. Concordamos com Dagnino (2002), quando ele afirma que os partidos políticos, mediadores tradicionais entre a sociedade civil e o Estado, limitaram sua representatividade na sociedade civil aos momentos eleitorais, tornando precária essa função mediadora.

Nesse sentido, as novas instâncias de intermediação desempenham funções que provocam alterações no governo representativo. A participação da sociedade civil nessas instâncias demonstra, como supõe Dagnino (2002, p. 279), "que o processo de construção democrática não é linear, mas contraditório e fragmentado", pois pressupõe que a sociedade civil nem sempre está voltada para o aprofundamento democrático e, muitas vezes, o desenho autoritário do Estado permanece resistente à participação. Ou seja, nas relações entre Estado e sociedade civil há um campo de disputas que é pleno de contradições, de diferentes interesses que nem

\footnotetext{
3 "A prática de representação é bem antiga, mas as suas raízes políticas mais significativas situam-se na história constitucional da Inglaterra a partir do séc. XIII. Desde 1264 os fidalgos do condado e os delegados dos burgos eram convocados em conjunto para se apresentarem ao rei. Desde o fim do séc. XIII, a ordem de convocação declarava que os representantes deviam ter pleno e suficiente poder para fazer e consentir nas deliberações conjuntas de nosso reino[...] a serem cumpridas em lugar e hora certos. Assim, de forma original, o Parlamento inglês evoluiu para uma assembleia representativa no sentido político durante os sécs. XIV, XV e XVI" (NETTO et al., 1986, p. 1063).
} 
sempre coadunam com processos democráticos e participativos. Mas, diante de alguns avanços conquistados nesse campo de lutas, há que se investir nesse movimento democrático e participativo para solidificar propostas de uma inserção mais incisiva da sociedade civil (principalmente se considerarmos que historicamente ela foi excluída de processos de tomada de decisão política).

Concordamos com Lavalle, Houtzager e Castello (2006a, p. 51) quando eles afirmam que os estudiosos do aprofundamento da democracia têm enfocado inovações institucionais que visam acolher "diversas formas de participação no desenho e implementação de políticas públicas". Esse aspecto torna-se relevante porque a compreensão das dinâmicas da representação política presentes no interior da sociedade civil constitui um ponto relevante no debate contemporâneo para o aprofundamento da democracia. As transformações da representação política (no sentido da pluralização de sujeitos e lugares envolvidos nesse processo) estão entre os elementos que podem proporcionar esse caminho.

Após o estabelecimento de novas formas de relação entre Estado e sociedade civil prescritos na Constituição Federal de 1988, vivencia-se uma "abertura" do Poder Executivo à participação de sujeitos societários investidos juridicamente como representantes de determinados segmentos e interesses da população no desenho, na implementação e na supervisão das políticas públicas, como colocam Lavalle, Houtzager e Castello (2006a).

Caccia-Bava (2001) assevera que, historicamente, tanto a afirmação de direitos quanto as experiências de participação popular são resultado de pressões, lutas sociais e movimentos de cidadãos que se insurgem contra as desigualdades. Quanto às experiências de participação, coloca:

Elas são resultado da ação de atores políticos concretos, de movimentos sociais, e também de conjunturas políticas particulares onde, seja por dificuldades das próprias elites consolidarem suas lideranças e representações, ou por outros motivos, surgem oportunidades para novos atores sociais se converterem em atores políticos e elegerem governantes, surgem oportunidades para se buscar uma nova regulação social. (CACCIA-BAVA, 2001, p. 22).
É importante pontuar que a participação de segmentos da sociedade civil pode ser o elemento central na configuração de distintos projetos políticos, ${ }^{4}$ como coloca Dagnino (2002). Do projeto ético-político que permeia a participação da sociedade civil depende o sucesso da gestão participativa. Os sujeitos societários deverão ter uma cultura ético-política forte e em constante revitalização, e isso depende de uma educação para a cidadania. É uma questão de consciência política, como apontam Nogueira (2004) e Pateman (1992).

As possibilidades de uma atuação conjunta do Estado e da sociedade civil são "sempre tensas e permeadas pelo conflito" (DAGNINO, 2002, p. 280). O grau dessa tensão decorre da aproximação ou da similaridade entre os diferentes projetos políticos que permeiam tal relação. $A$ autora ressalta o caráter de construção histórica dessa relação, no sentido de que essas relações "são objeto da política e, portanto, transformáveis pela ação política” (DAGNINO, 2002, p. 281).

Voltamos aqui a pontuar que diferentes projetos políticos orientam as relações que ocorrem entre a sociedade civil e o Estado. Os conflitos são resultados de confrontos entre projetos políticos distintos. Lavalle, Houtzager e Castello (2006a) e Caccia-Bava (2001) afirmam que essa nova relação entre Estado e sociedade civil, baseada na participação, na transformação da representação política e no reconhecimento da pluralidade e da legitimidade dos interlocutores na esfera pública (DAGNINO, 2002) é requisito para o aprofundamento da democracia.

Nesse sentido, autores como Nogueira (2004) e Dagnino, Olvera e Panfichi (2006) preconizam a superação do antagonismo entre representação e participação, visualizando a democracia participativa como uma resposta às características excludentes das democracias eleitorais e ampliando a democracia mediante a participação da sociedade civil nos espaços públicos. Lüchmann (2007) aponta o fato de que a participação não substitui a representação, mas

\footnotetext{
4 "A noção de projeto político, tomada como aquilo que orienta aquela ação [...] o termo projetos políticos num sentido próximo da visão gramsciana é utilizado para designar os conjuntos de crenças, interesses, concepções de mundo, representações do que deve ser a vida em sociedade que orientam a ação política dos diferentes sujeitos." (DAGNINO, 2002. p. 281-282).
} 
a reconfigura, constituindo uma chave da boa representação, ou seja, ambas se relacionam e são complementares no processo democrático.

Vázquez (2001, p. 86), ao pronunciar-se sobre a relação complementar entre democracia e participação, coloca:

Como a democracia exige uma participação consciente e racional na tomada de decisões que afetam a comunidade, e toda vez que esta participação é uma exigência de liberdade, a democracia é um valor a que não se pode deixar de aspirar [...] a democracia, dada sua necessidade de estender-se ou aprofundar-se, é subversiva.

Para o autor, aquele que ocupar o espaço participativo de forma "consciente e racional" tentará colocar em práticas seus preceitos e perspectivas. Nesse sentido, a democracia mostra seu caráter "subversivo", pois não está definido quem ocupará determinado espaço, mas quem se fizer mais forte e presente. Por esse motivo, há que se fortalecer os segmentos populares que estiveram historicamente alijados de processos democráticos e participativos no Brasil, no sentido de instrumentalizá-los para esse empreendimento político e social. Os espaços de relação complementar entre representação e participação, institucionalizados ou não, são espaços férteis para a busca dessa tendência contra-hegemônica que mostra seus primeiros passos na história brasileira. ${ }^{5}$

$\mathrm{Na}$ defesa da relação complementar entre representação e participação, os participacionistas incorporam pressupostos da democracia direta no interior da democracia representativa, enfatizando a inclusão dos setores excluídos do debate político e a dimensão pedagógica da política, como pressupõem Lüchmann (2007) e Pateman (1992). A partir de então, a democracia deliberativa vai dar centralidade à questão da participação, com uma nova concepção acerca da legitimidade política. A partir das fragilidades da democracia representativa, a democracia de-

\footnotetext{
${ }^{5}$ Com isso não queremos afirmar que na história brasileira não houve ricos momentos de expressão e de lutas sociais por direitos, por cidadania, por justiça social; mas que estas lutas foram, em termos quantitativos, menores que as expressões hegemônicas de poder e mando presentes nesta história. Sobre a configuração da sociedade brasileira, ver Otavio Ianni (1984), Florestan Fernandes (1975) e Coutinho (2000).
}

liberativa impõe que a legitimidade das decisões políticas advém de processos de discussão que, orientados pelos princípios da inclusão, do pluralismo, da igualdade participativa, da autonomia e do bem-comum, conferem um reordenamento na lógica de poder tradicional. Nessa perspectiva, temos concebida a ideia de que:

[...] o poder deve organizar-se democraticamente através de instituições que, construídas coletivamente através da discussão pública, mediam as relações entre os interesses individuais e coletivos, na formação do interesse público a ser implementado pelo complexo administrativo estatal. (LÜCHMANN, 207, p. 144).

A partir da ampliação da democracia, surge uma nova noção de representação política no seio das organizações civis, com o reconhecimento da relevância da representação política exercida por tais organizações no sentido de conectar ao Estado, por meio de espaços participativos, os segmentos da população mal ou sub-representados.

Como exemplo desses espaços, trazemos os conselhos gestores de políticas públicas. Porém, cabe-nos lembrar de que, com frequência, o poder deliberativo dos conselhos se transforma em uma função consultiva ou até mesmo legitimadora de decisões tomadas previamente, ou seja, a partilha do poder tem um caráter limitado e restrito. Esse conflito tem origem em concepções políticas resistentes a democratização dos processos de tomada de decisão, como supõe Dagnino (2002), enfraquecendo o poder deliberativo dessa instância de participação.

Em seus estudos, Lavalle, Houtzager e Castello (2006b) apontam um aspecto dual da representação política exercida por organizações civis, ${ }^{6}$ levantando possibilidades de efeitos não democráticos devidos à inexistência ou à precariedade de mecanismos obrigatórios de sanção ou controle entre as organizações civis e os segmentos sociais por elas representados, "em nome de quem e mediante quais mecanismos

\footnotetext{
6 "As organizações civis estão desempenhando um novo papel ativo na representação política, papel diferente do desempenhado por partidos e sindicatos. Desta forma, a grande maioria das organizações não utiliza mecanismos eleitorais para estabelecer sua representatividade" (LAVALLE; HOUTZAGER; CASTELLO, 2006b, p. 44).
} 
de controle e responsividade representam as organizações civis" (LAVALLE; HOUTZAGER; CASTELLO, 2006b, p. 46).

Esses autores supõem que a representação política está restrita aos processos eleitorais e que por esse motivo as funções de representação política exercidas por organizações civis tornam-se passíveis de críticas de falta de representatividade - ora pela ausência de dispositivos de autorização (voto), ora por evasão de mecanismos de controle e sanção. Ainda para esses autores, a situação pode ser superada a partir do compromisso das organizações civis de representar, o qual é maior que essa fragilidade da representação: "centrando a atenção no compromisso representativo do representante e na sua identificação com o representado" (LAVALLE; HOUTZAGER; CASTELLO, 2006b, p. 47). Portanto, se cairmos no discurso de que a fragilidade da representação é maior que o compromisso assumido pelos diferentes de canais de participação democrática, contribuiremos para o retrocesso das conquistas democráticas já alcançadas.

As mudanças nas configurações do Estado, principalmente com a Constituição Federal de 1988, introduziram o controle social ${ }^{7}$ na gestão pública, o que tem sido estímulo e produto do protagonismo das organizações civis, agora com funções de representação política. Essa nova função das organizações civis levanta questões sobre a relação entre representantes e representados ${ }^{8}$ no cenário da representação política tradicional, afinal "a separação entre representante e representado é característica constitutiva da representação política moderna" (LAVALLE; HOUTZAGER; CASTELLO, 2006b, p. 46). O modelo de representação política (mandato representativo mediante eleições) foi

\footnotetext{
${ }^{7}$ Segundo Correia (2002), a partir da segunda metade da década de 1980 , a participação social nas políticas públicas foi concebida na perspectiva do controle social, no sentido de os setores organizados da sociedade participarem em suas formulações, no acompanhamento de suas execuções, até a definição dos recursos para que estas atendam aos interesses da coletividade.

8 "O representado, sempre pessoas cuja vontade se consubstancia de maneira em maior ou menor grau direta e concreta (voto, reclamo, petição), ou de maneira necessariamente indireta e abstrata (nação, tradição, bem comum); o representante, intermediário e guardião dos interesses do representado" (LAVALLE; HOUTZAGER; CASTELLO, 2006b, p. 50).
}

historicamente construído para desempenhar funções que não coincidem com o perfil das organizações civis. Contudo, "o comprometimento com os interesses dos representados é um componente vital da representação [...] o melhor dispositivo para garantir a autenticidade - sua representatividade - seria a existência de um compromisso representativo genuíno" (LAVALLE; HOUTZAGER; CASTELLO, 2006b, p. 47). Assim, seguindo o caminho apontado por Rousseau (2002), a vontade geral deve estar acima dos interesses particulares.

Temos então que o compromisso ético-politico dos representantes diante de seus representados também é um elemento constitutivo, é regra para o bem representar, sendo, portanto, um aspecto a ser destacado neste estudo. É sabido que atualmente convivemos com uma crise de representação, a qual está fundada na "fragilidade ou inexistência da relação entre eleitor e eleito, entre os cidadãos e seus representantes." (CACCIA-BAVA, 2001, p. 38). Uma representação só pode funcionar plenamente se houver conteúdo, com uma presença ativa dos cidadãos que dão um mandato a seus representantes após debatendo seu conteúdo e avaliando seus resultados. Nesse sentido, participação e representação estão unidas e articuladas com a noção de democracia. Portanto, aqueles que se propõem a representar segmentos da sociedade devem ter o compromisso e o conhecimento de que "para cumprirem seu papel de representação necessitam inaugurar uma nova relação com seus representados, isto é, reforçar suas relações com as comunidades locais e tornarem-se agentes estimuladores da organização da sociedade civil" (CACCIA-BAVA, 2001, p. 48).

Os espaços de participação foram criados para que segmentos sub-representados no Poder Executivo e Legislativo tivessem canais de acesso ao poder, levando consigo suas demandas e visões de mundo. "Se os representantes falham em levar os anseios da população, eles contribuem para que estes espaços fiquem desacreditados e deixem de ser uma alternativa aos mecanismos tradicionais de representação" (DOWBOR; HOUTZAGER; SERAFIM, 2008, p. 7).

A mera existência da representação, mesmo que legalmente instituída, não garante a representatividade ou a correspondência com a 
vontade ou os interesses dos representados. "As eleições constituem um mecanismo de sanção sobre os representantes [...] e tendem a estimular a sensibilidade destes perante às demandas $e$ necessidades dos representados" (LAVALLE; HOUTZAGER; CASTELLO, 2006a, p. 55). Ou seja, o representante deve Representar (com $R$ maiúsculo) o interesse dos representados.

Concordamos com os autores quando eles supõem que a representação política necessita de complementaridade entre representação e representatividade, entre representante e representado, e que o seu desdobramento pode ser visto como o componente legal da representação versus o seu componente substantivo, ou seja, a vontade do representado. Assim,

[...] se privilegiado o polo formal-institucional do representante, perde-se o conteúdo substantivo da representação como atuação para o interesse ou benefício do representado; se privilegiado o polo substantivo de formação de vontade do representado, perde-se o conteúdo político da representação enquanto cristalização institucional arquitetada para organizar o governo da e sobre a sociedade. (LAVALLE, HOUTZAGER, CASTELLO, 2006a, p. 57).

Essa complementaridade supõe que a autonomia política do representante não pode ser perseguida a ponto de romper sua relação com os representados, ao passo que o fortalecimento da representatividade também não pode ser alcançado à custa da anulação dessa autonomia. Assim, as conexões devem ser alimentadas, pois somente a partir das mesmas o conteúdo substantivo da representação pode ser mantido. Sobre esse aspecto, é importante averiguar quais são as conexões entre representantes e representados, como se manifestam Lavalle, Houtzager e Castello: "Definir em termos concretos quem ou o que deve ser efetivamente representado, ou se a representação política pode ser reputada como realmente representativa, é questão espinhosa mesmo no contexto das democracias" (LAVALLE; HOUTZAGER; CASTELLO, 2006a, p. 59-60).

Bobbio, Matteucci e Pasquini (1998, p. 1104) ao se manifestarem sobre a representação-espelho, aquela que responde as exigências de ordem simbólica e psicológica, citam o seguinte exemplo: "os grupos pouco integrados, marginais de um sistema político terão necessidade não só de representantes que 'zelem por seus interesses', mas ainda de representantes que, pelas suas características pessoais, neles se possam identificar e sentir-se 'presentes' na organização política.

Mendes (2007), ao analisar a representação política, coloca que o representante político representa não apenas uma pessoa, mas toda uma coletividade, o que torna muito complexas a determinação dos interesses. Os representantes não podem ser contrários aos representados, pois isso significa uma separação entre eles. O representante deve ser dotado de capacidade de ação e julgamento, com certo grau de liberdade para deliberar, mas não pode estar em oposição aos desejos do representado. A representação dá-se não pelas ações dos representantes, mas por uma atividade contínua de responsividade, ou seja, de resposta. É preciso que existam arranjos institucionais para que os representados possam exigir uma resposta sempre que se sentirem lesados em sua vontade. "Mais do que exercício direto do poder, é preciso haver acesso ao poder" (MENDES, 2007, p. 149). Supomos que, para a efetivação da representação, é necessária uma participação política, compreendida a partir de Nogueira (2004) como uma organização da vida social em seu conjunto, consolidando, protegendo e dinamizando a cidadania, sendo os cidadãos seus protagonistas.

O acesso ao poder a partir da participação política não ocorre sem lutas sociais, as quais são consideradas por Montaño e Duriguetto (2010) como constitutivas da luta de classes. "Lutas que não podem esperar a 'grande revolução' para resolver problemas pontuais, mas cujos objetivos de curto prazo [...] não necessariamente são antagônicos à finalidade de longo prazo" (MONTAÑO; DURIGUETTO, 2010, p. 119).

Portanto, a participação de sujeitos sociais em diferentes espaços, e realizando diferentes conquistas (cotidianas, locais, parciais), é um dos elementos que compõem a visualização ou concorrem para a edificação de projetos societários mais abrangentes. As práticas desenvolvidas nesses espaços não se encerram em si mesmas, mas podem e devem buscar teleologicamente questões sociais mais amplas.

Continuando a pensar sobre os elementos constitutivos - ou regras da representatividade -, Dowbor, Houtzager e Serafim (2008) acreditam 
que, no movimento de informação e prestação de contas entre representantes e representados, ficam claros não somente a responsabilidade do representante frente ao grupo de seus representados, mas também o movimento contrário: é também responsabilidade dos representados, ou seja, do coletivo, subsidiar o representante com informações, opiniões e discussões realizadas naquele grupo, fórum, movimento ou conselho. A qualidade da representação exercida depende não apenas do empenho do representante em prestar contas e buscar informações, mas também da capacidade do grupo de fornecer as informações de que ele necessita para representá-lo e exigir que ele preste contas de sua atuação, estabelecendo uma relação de complementaridade entre as partes.

Como regra, esse movimento que compõe o fenômeno da representatividade é fácil de ser defendido, porém Demo (2001) alerta que "a meta implícita por parte da elite privilegiada é evitar o controle democrático, para que as regras do jogo não venham a ser questionadas e mudadas" (DEMO, 2001, p. 25).

Portanto, enfatizamos que, para que a relação entre representante e representado obtenha êxito, é necessário que sujeitos políticos estejam envolvidos nesse processo democrático para questionar as regras, ou, nos termos de Vázquez (2001), sujeitos participantes no enfrentamento das dificuldades estruturais colocadas para a efetivação dos preceitos democráticos.

Somente é possível falar de democracia enquanto existir participação, mesmo que para esta se imponham limites - uma democracia como regime de convivência numa sociedade determinada e como método ou conjunto de procedimentos para adotar as decisões coletivas que entranham toda participação, como supõe Vázquez (2001):

A democracia é antes de tudo participação, e isto presume não só conceber a presença do coletivo no sujeito participante e no lugar em que participa, mas também na forma e no objeto de sua participação. A participação de um presume a dos demais e, mesmo assim, o respeito e a tolerância em relação a eles. (VÁZQUEZ, 2001, p. 93).
O papel do representante é agir em benefício dos interesses dos representados, mas isso não quer dizer que é necessário cair no particularismo. O representante deve defender os interesses de seu segmento sem deixar de reconhecer as necessidades e demandas de outros segmentos. A representação requer um equilíbrio entre os interesses dos representados, a capacidade de negociação no espaço onde a representação ocorre (conselho, por exemplo) e o bem maior (da cidade, região ou país). "A verdadeira democracia reside no reconhecimento de outros grupos, suas necessidades e legitimidade como cidadãos" (DOWBOR; HOUTZAGER; SERAFIM, 2008, p. 19).

Outro elemento que torna relevante a questão da representação é a pluralização dos espaços da participação da sociedade civil na gestão das políticas públicas, e que essa sociedade almeje interferir positivamente na qualidade dos serviços públicos e na construção de uma sociedade menos desigual. Tais aspectos não serão resolvidos de forma mágica, mas sim nos enfrentamentos, no debate público, na composição de estratégias que fortaleçam a democracia participativa ou direta.

Os modelos participativos apresentam um critério de legitimidade ancorado na ideia de que as decisões políticas devem ser tomadas por meio do debate público. As diferenças com relação ao modelo da democracia representativa são marcantes, já que esta incorpora a participação da população no processo de discussão e de tomada de decisões políticas. Nesse formato, as diferentes práticas de participação e representação visam superar os limites da representação eleitoral. ${ }^{9}$ Utilizemos como exemplo os conselhos gestores de políticas públicas.

\footnotetext{
9 "as experiências participativas inauguram novos mecanismos e relações de representação política que apresentam especificidades e diferenças substantivas com o modelo da representação eleitoral [...] seja por combinarem, em seu interior, mecanismos de representação com participação direta; seja por articularem, de forma imediata, participação com representação da sociedade civil" (LÜCHMANN, 2007, p. 146).
} 
Os Conselhos Gestores e Orçamentos Participativos $(\mathrm{OPs})^{10}$ passam a se constituir em referências centrais de experiências participativas no país, dando impulso ao desenvolvimento de um debate teórico sobre participação política e democracia, o que amplia, sobremaneira, uma concepção de política voltada estritamente para o campo de ação exclusivo dos representantes políticos que orientam as suas estratégias e escolhas políticas a partir do jogo eleitoral. (LÜCHMANN, 2008, p. 87).

A constituição dos conselhos gestores de políticas públicas garantiu a eleição de dezenas de milhares de conselheiros e conselheiras que hoje atuam nesses espaços de cogestão, representando as comunidades das quais são oriundos, conforme coloca Caccia-Bava (2001). Porém, vem sendo realizados estudos sobre alguns limites existentes na materialização das propostas de cogestão, advindos muitas vezes da resistência de governos à participação social, do despreparo dos conselheiros e da cultura política impregnada na sociedade:

Os conselhos viram espaços de cooptação, os governos não Ihes reconhecem ou atribuem poderes de decisão. [...] Espera-se, como num passe de mágica, que aqueles que nunca decidiram passem de imediato a disputar com sucesso, em pé de igualdade, com os representantes governamentais. (CACCIA-BAVA, 2001, p. 22).

Sabemos que a história brasileira não foi uma incentivadora de processos participativos, democráticos, tampouco do exercício da representação na verdadeira acepção da palavra. Mas isso não quer dizer que temos de continuar esse caminho traçado histórica e hegemonicamente. Os diversos espaços construídos pela sociedade brasileira - aqui, tratamos especificamente dos

\footnotetext{
10 Dias (2008), baseado em Boaventura Sousa Santos, concebe Orçamento Participativo como uma estrutura e um processo de participação dos cidadãos na tomada de decisão sobre os investimentos públicos municipais, com base em três princípios: 1) participação aberta dos cidadãos, sem discriminação positiva atribuída às organizações comunitárias; 2) articulação entre democracia representativa e direta, que confere aos participantes um papel essencial na definição das regras do processo; 3 ) definição das prioridades de investimento público processada de acordo com critérios técnicos, financeiros e outros de caráter mais geral, que se prendem, sobretudo, com as necessidades sentidas pelas pessoas. (DIAS, 2008).
}

conselhos, que reúnem mais de cem mil conseIheiros em todo Brasil (DOWBOR; HOUTZAGER; SERAFIM, 2008) podem exercitar o aprendizado democrático e apresentar para a sociedade novas formas de participação para fortalecer uma contracultura a partir da democratização das relações sociais e de poder.

A representação da sociedade civil exercida nos espaços de participação política se diferencia daquela exercida pelos representantes políticos eleitos e apresenta inúmeros desafios de representação enfrentados pelos representantes. Conforme Dowbor, Houtzager e Serafim (2008), se somarmos todos os conselhos no Brasil, chegaremos ao número de $18 \mathrm{mil}$, com mais de 100 mil conselheiros, o que supera o número de vereadores em todos os municípios. ${ }^{11}$ Existem dezenas de milhares de conselheiros no Brasil, atuando como representantes em nome de comunidades, grupos e organizações.

Será que os mais de 100 mil conselheiros são efetivamente representativos? Essa é uma questão importante, porque a falta de representatividade pode deslegitimar os espaços de participação da sociedade. Esse é um dos desafios que temos para levar adiante as perspectivas de aprofundamento e qualificação da democracia no Brasil.

\section{Sujeitos representativos}

Após essas considerações, partimos para o debate sobre a importância da constituição de sujeitos representativos/participativos para contribuir com processos democráticos de micro e amplo espectro.

Montaño e Duriguetto (2010) trazem a questão da determinação do sujeito da transformação social, que representa uma dimensão fundamental na tradição marxista para pensar as lutas e o processo revolucionário. "São as determinações realmente existentes, e não a ideia, a vontade, o que caracteriza o sujeito de transformação social" (MONTAÑO; DURIGUETTO, 2010, p. 128), ou seja, são as contradições, os

\footnotetext{
${ }^{11}$ Os autores Dowbor, Houtzager e Serafim (2008) se reportam a duas pesquisas sobre representação desenvolvidas em São Paulo pelo Centro Brasileiro de Análise e Planejamento (CEBRAP), pelo Institute of Development Studies (IDS) e pelo Instituto Pólis, entre 2001 a 2006.
} 
interesses dos diferentes grupos sociais, a consciência social e a correlação de forças sociais que configuram o sujeito da transformação social. Desse fundamento, depuramos que o sujeito é determinado pelo contexto em que vive: pelas ideologias, pelos aprendizados, pelo conjunto de elementos sociopolíticos que se expressam nas relações socioculturais e econômicas. Portanto, o sujeito não se faz sozinho, mas nas relações que estabelece com o meio em que vive. Apreendemos que essas relações podem ou não favorecer a constituição de sujeitos participantes, conscientes, ativos e representativos.

Os autores Montaño e Duriguetto (2010) colocam que Marx e Engels, no Manifesto comunista, veem como sujeito da transformação social o proletariado, visto como sujeito da superação da ordem do capital - devido ao fato de constituírem os produtores diretos da riqueza, que lhes é expropriada mediante a exploração capitalista, dona dos meios de produção. "Por ser a classe explorada da riqueza que produz, o proletariado tem a missão histórica de transformar a ordem social capitalista, a ordem que o oprime e o explora" (MONTAÑO; DURIGUETTO, 2010, p. 128). Porém, na contemporaneidade, o sujeito da transformação social pode ser visto de outra forma, como afirma, por exemplo, Borón ${ }^{12}$ (2010): "Não existe um único sujeito - e menos ainda um único sujeito pré-constituído - da transformação socialista." (BORÓN, 2010, p. 115).

$\mathrm{Na}$ perspectiva marxista, autores como Montaño e Duriguetto (2010) lembram que, no século XIX, diante das condições históricas do período, Marx e Engels colocavam o proletariado como sujeito central da transformação social. Outros autores da tradição marxista ampliam o leque de categorias de sujeitos de transformação, dadas as condições históricas que marcam a sociedade contemporânea. Assim, o crescente protagonismo adquirido pelas massas populares na oposição ao capitalismo amplia o leque de sujeitos presentes na contemporaneidade.

Borón (2010) sinaliza para uma leitura sobre os novos contornos da conjuntura con-

\footnotetext{
${ }^{12}$ Atílio Borón é um cientista político argentino marxista. É secretário executivo do Conselho Latino-americano de Ciências Sociais (Clacso) e professor de Teoria Política na Universidade de Buenos Aires. Autor de Estado, Capitalismo e Democracia na América Latina e A coruja de Minerva.
}

temporânea e dos sujeitos (claramente no plural) que a compõem, indicando que estes podem congregar lutas coletivas em busca de novas perspectivas de vida em sociedade. Essa proliferação de sujeitos "não decreta a abolição das leis do movimento da sociedade de classes: só significa que a cena social e política se tornou mais complexa" (BORÓN, 2010, p. 118).

Portanto, as novas configurações do capitalismo contemporâneo abrem flancos para a emergência de novas formas e expressões da subalternidade inerente ao sistema. Por exemplo, os movimentos sociais, que manifestam novas demandas, mas que são inerentes à dinâmica do capital - e são também expressões do protagonismo das classes sociais:

[...] moradores de bairros, jovens, ecologistas, pacifistas, defensores dos direitos humanos [...]. Esses novos movimentos não são uma simples miragem [...] mas expressam novos tipos de contradições e reivindicações geradas pela renovada complexidade e conflitividade da sociedade capitalista. (BORÓN, 2010, p. 119-120).

Contradições e reivindicações, diríamos, geradas pelas desigualdades sociais também advindas desta complexidade. $\mathrm{O}$ autor complementa dizendo que não há um, mas vários sujeitos, que poderão, num processo organizativo, na condição de classe social com consciência de seu protagonismo, construir os enfrentamentos para a instauração de novos padrões de civilidade.

Assim se conforma uma tendência no debate contemporâneo sobre a centralidade dos sujeitos potencialmente capazes de empreender esforços para a transformação social. Não um único sujeito. Paralelamente às novas configurações societárias, emerge uma pluralidade de sujeitos.

Nesse mesmo contexto, há outros sujeitos privilegiados que também têm a missão de "transformar a realidade", e, mais especificamente, de transformar modelos de gestão tradicional de políticas públicas. Eles podem ser vistos como sujeitos representativos, e podem contribuir para o aprofundamento da democracia - como os cem mil conselheiros que atuam hoje no Brasil. Nesse sentido, Duriguetto (2011) afirma: 
O espaço das conferências e dos conselhos de direitos, criados a partir da Constituição de 1988, são espaços importantíssimos da luta política, as conferências, os fóruns. Estes espaços somente irão interferir na gestão e na organização das políticas sociais se eles efetivamente funcionarem, se forem ocupados com qualidade. Quando falo ocupado com qualidade, me refiro aos conselheiros que tomam assento nos Conselhos, que participam das Conferências, os cidadãos comuns que não têm assento em conselhos. Depende da capacitação desse sujeito para um efetivo funcionamento e para a qualidade deste espaço participativo, a densidade política deste espaço depende da densidade política destes que tomam assento. (DURIGUETTO, em palestra proferida na UEPG em 23 de março de 2011).

Aqualificação desses importantes espaços para a luta política depende da capacidade de sustentação política daqueles que compõem esses espaços, o que caracteriza o grande desafio da contemporaneidade, uma vez que apenas parte desses sujeitos está "capacitada" para tanto. No enfrentamento desse desafio, a construção de sujeitos políticos voltados para processos de transformação social inclui o trabalho dos conselhos.

Os autores Montaño e Duriguetto (2010, p.130) apontam como noção de emancipação política, o: "conjunto de direitos políticos e sociais que garantem uma liberdade e uma igualdade formais dos cidadãos - a liberdade e a igualdade perante a lei, portanto, meramente jurídicas". Então, se esses cem mil conselheiros estivem empreendendo esforços pela emancipação política dos segmentos que representam (conquista de direitos civis, políticos, trabalhistas e sociais), representarão uma das conquistas importantes para o acesso aos direitos e à igualdade, mas, em longo prazo, não poderão perder de vista processos emancipatórios mais amplos.

Para que os conselheiros se configurem como um dos sujeitos representativos, ainda é necessário um processo socioeducativo de longo prazo. Nesse sentido, Demo (2001) afirma:

A contribuição fundamental da educação está em fazer de alguém um sujeito capaz de história própria, ou seja, de combater a pobreza política. [...] O impacto mais direto da educação não é econômico, mas político - forjar um sujeito capaz de reagir, organizar-se, combater, partir para a luta. [...] Controle democrático só é efetivo na população que sabe pensar, teórica e praticamente, ou seja, sabe desenvolver consciência crítica [...] Educação pode ser fator central. (DEMO, 2001, p. 93-94).

Concordamos com Demo (2001), entendendo que a educação é fundamental para o desenvolvimento da consciência crítica que envolve os sujeitos participativos. Dentre estes podem estar os conselheiros, que muito poderão fazer no combate à pobreza política, e, consequentemente, na ampliação da democracia.

O caso dos conselheiros é um exemplo da possibilidade de construção de sujeitos políticos / representativos, desde que capacitados ética e politicamente para gerir políticas públicas e contribuir nos processos de superação das desigualdades sociais. Esse é mais um elemento que compõe o desafio da representatividade.

Outro elemento importante para avançar nesse debate é o enfrentamento da dificuldade de interação entre representantes governamentais e da sociedade civil pelos conselhos gestores. Esses são espaços caracterizados hegemonicamente pela superposição de soberanias, uma vez que o governo eleito democraticamente para agir no lugar de seus constituintes precisa compartilhar o poder decisório com sujeitos representativos da sociedade civil. Essa tem sido uma relação conflituosa no âmbito do Poder Executivo municipal, que se recusa a dar poder de fato aos conselheiros, conforme Tatagiba (2002).

A crítica comum aos conselhos é que os representantes da sociedade civil têm ligações muito frágeis com os grupos populares que deveriam representar. "De uma forma geral, os conselheiros não governamentais têm encontrado muito pouco respaldo e acompanhamento de suas ações por parte das entidades que representam" (TATAGIBA, 2002, p. 65). Sem conseguir despertar a atenção de seu público, os conselheiros tendem a agir de acordo com seus interesses pessoais, em detrimento dos interesses das associações que representam.

Na relação complementar entre a democracia representativa e a democracia participativa, a representação dos sujeitos deve demonstrar os interesses, necessidades e aspirações da sociedade, seguindo um conjunto de regras para 
sua efetivação, como vimos na sistematização traçada neste estudo. Também destacamos que o conjunto de regras não se esgota em si mesmo, dependendo da sua materialização o fortalecimento de perspectivas que contribuam com a efetivação de processos democráticos substanciais (aqueles que teleologicamente extrapolam as regras e chegam à essência da democracia: compatibilizar a igualdade e interesse geral).

\section{Considerações finais}

Como vimos, a democracia preconizada no período clássico era a democracia direta, tida como regra da convivência, e a democracia representativa era a exceção. Atualmente, com a proposta de ampliação das estratégias da democracia direta associadas à democracia representativa, desaparece a assembleia na qual todos os cidadãos participavam do processo decisório, mas não a exigência de visibilidade do poder, como coloca Bobbio (2000). Assim, tornar os processos decisórios visíveis publicamente faz parte dos preceitos democráticos atuais.

Podemos sistematizar como principais elementos teóricos sobre a categoria "representatividade" os posicionamentos dos autores que apresentamos a seguir. A democracia pode ser vista como método, sendo necessário para tal um conjunto de regras. Nessas regras, inclui-se a eleição daqueles aos quais é atribuído o poder, bem como a regra da maioria, que supõe que a decisão coletiva é apenas um dos elementos para o funcionamento do sistema democrático (BOBBIO, 2000; VÁZQUEZ, 2001). Ainda dentro desse conjunto de regras, o verdadeiro representante é aquele que prioriza os interesses gerais. Segundo Rousseau (2002), a vontade geral é indestrutível e deve estar acima dos interesses particulares.

A essência da representação política que tentamos demonstrar nesse texto - é a autorização para agir que advém dos eleitores/ representados (BOBBIO, 2000). O representante deve expressar os interesses dos representados. Esse é o componente substantivo da representação. Então, como ensinam Bobbio, Matteucci e Pasquino (1998), representar é possuir certas características que espelham as dos sujeitos representados.
A representação política nas democracias contemporâneas sofreu transformações profundas, principalmente na perda das preferências do eleitorado pelos partidos políticos (LAVALLE; HOUTZAGER; CASTELLO, 2006a). Para Dagnino (2002), os partidos políticos limitaram sua representatividade às eleições, tornando precária essa função mediadora.

Atualmente, a representação segue novos caminhos, como o controle social (LAVALLE; HOUTZAGER; CASTELLO, 2006a). Novas instâncias de intermediação provocam alterações no governo representativo, como a participação de segmentos da sociedade civil por meio da pluralização de sujeitos envolvidos nos processos democráticos.

A democracia participativa é vista por Nogueira (2004) e Dagnino, Olvera e Panfichi (2006) como uma resposta às características excludentes das democracias eleitorais. Lüchmann (2007) aponta que a participação reconfigura a representação.

Para tanto, é necessária a constituição de sujeitos políticos representativos/participativos. Segundo Borón (2010), não existe um único sujeito. Há outros privilegiados que também são potencialmente capazes de uma inserção pública que represente as demandas originárias de diferentes segmentos sociais, como os $100 \mathrm{mil}$ conselheiros e conselheiras dos conselhos gestores de políticas públicas espalhados pelo país (DOWBOR; HOUTZAGER; SERAFIM, 2008). Para que a representatividade destes expresse substancialmente elementos democráticos, ela deve contemplar e/ou conter alguns elementos:

- o poder (tomada de decisões) submetido ao controle da sociedade (VÁZQUEZ, 2001);

- os interesses gerais acima dos interesses particulares (ROUSSEAU, 2002);

- as relações efetivas entre representantes e representados. Entre elas: a autorização para agir (BOBBIO, 2000), a troca de informações entre ambos os lados e a prestação de contas (DOWBOR; HOUTZAGER; SERAFIM, 2008);

- o comprometimento com os interesses dos representados (LAVALLE; HOUTZAGER; CASTELLO, 2006b). 
Ressaltamos que este artigo não tem a intenção de ser prescritivo ou normativo, mas sim de apresentar uma discussão sintética sobre os fundamentos e elementos constitutivos da questão da representatividade de sujeitos sociais que têm se inserido em diferentes níveis de gestão social, de deliberação, de consultoria nos municípios, estados e federação brasileira. Existem fragilidades (determinadas pela história da cultura política brasileira) para a efetivação dessa estratégia (ou recurso, mecanismo de participação social). Porém, sabemos que existem experiências exitosas nesse sentido: sujeitos sociais têm colocado em prática os fundamentos e regras de representatividade com vistas a mudanças na lógica das relações entre representantes e representados. Tornar públicas essas experiências poderá provocar a multiplicação de experiências nesse sentido e contribuir para que as "novas regras" sejam absorvidas naturalmente pelo "novo" desenho democrático, contra-hegemônico, que está sendo construído no país.

\section{Referências}

BOBBIO, N.; MATTEUCCI, N.; PASQUINO, G. Dicionário de política. Trad. Carmem $C$. Varriale et al. 11.ed. Brasília: Ed. Universidade de Brasília, 1998, v.2.

BOBBIO, N. Teoria geral da política: a filosofia política e as lições dos clássicos. Trad. Daniela Beccaccia Versiani. Rio de Janeiro: Campus, 2000.

BORÓN, A. O socialismo no século 21: há vida após o neoliberalismo? Trad. Fabiane Tejada da Silveira et al. São Paulo: Expressão Popular, 2010.

CACCIA-BAVA, S. Participação, representação e novas formas de diálogo público. São Paulo: Pólis, Programa Gestão Pública e Cidadania / EAESP/ FGV, 2001.

CORREIA, M. V. C. Que controle na política de assistência social? Revista Serviço Social \& Sociedade, São Paulo, n.72, p.119-44, 2002.

COUTINHO, C. N. Cultura e sociedade no Brasil. 2.ed. Rio de Janeiro: DP\&A, 2000.

DAGNINO, E.; OLVERA, A. J.; PANFICHI, A. (Orgs.). A disputa pela construção democrática na América Latina. São Paulo: Paz e Terra, Campinas: Ed. Unicamp, 2006.
DAGNINO, E. Sociedade civil, espaços públicos e a construção democrática no Brasil: limites e possibilidades. In: (Org.). Sociedade civil e espaços públicos no Brasil. São Paulo: Paz e Terra, 2002, p.279-301.

DEMO, P. Cidadania pequena: fragilidades e desafios do associativismo no Brasil. Campinas: Autores Associados, 2001. (Coleção Polêmicas do nosso tempo, n.80).

DIAS, N. Orçamento participativo: animação cidadã para a participação política. Lisboa: Associação In Loco, abr. 2008. Disponível em: <http://www.in-loco.pt/ site/parameters/inloco/files/File/upload/Publicacoes/ Livro_OP_AF_web.pdf>. Acesso em: jun. 2011.

DOWBOR, M.; HOUTZAGER, P.; SERAFIM, L. Enfrentando os desafios da representação em espaços participativos. São Paulo: CEBRAP / IDS, 2008.

DURIGUETTO, M. L. Sociedade civil e democracia. Palestra proferida na Universidade Estadual de Ponta Grossa, 23 mar. 2011. Ponta Grossa: UEPG, 2011.

FERNANDES, F. Sociedade de classes e subdesenvolvimento. 3.ed. Rio de Janeiro : Zahar, 1975.

IANNI, O. Origens agrárias do Estado brasileiro. São Paulo: Brasiliense, 1984.

LAVALLE, A. G.; HOUTZAGER, P.; CASTELLO, G. Democracia, pluralização da representação e sociedade civil. Revista Lua Nova, São Paulo, n.67, p.49-103, 2006a.

Representação política e organizações civis: novas instâncias de mediação e os desafios da legitimidade. Revista Brasileira de Ciências Sociais, São Paulo, v.21, n.60, p.43-66, 2006b.

LAVALLE, A. G. et al. Formas de representação nos Conselhos Setoriais de Políticas Públicas de São Paulo. São Paulo: PÓLIS / CEBRAP / IDS, Relatório de Pesquisa, (s/d).

LÜCHMANN, L. H. H. A representação no interior das experiências de participação. Revista Lua Nova, São Paulo, n.70, p.139-70, 2007.

Participação e representação nos conselhos gestores e no orçamento participativo. Caderno CRH, Salvador, v.21, n.52, p.87-97, jan./abr., 2008.

MARX, K.; ENGELS,F. Manifesto do Partido Comunista. Trad. Pietro Nassetti. 2.ed. São Paulo: Martin Claret, 2000. 
MENDES, D. C. V. R. Representação política e participação: reflexões sobre o déficit democrático. Revista Katálysis, Florianópolis, v.10, n.2, p.143-53, jul./dez., 2007.

MONTAÑO, C.; DURIGUETTO, M. L. Estado, classe e movimento social. 2.ed. São Paulo: Cortez, 2010.

NETTO, A. G. M. et al. Dicionário de ciências sociais. Rio de Janeiro: Ed. Fundação Getúlio Vargas, 1986.

NOGUEIRA, M. A. Um Estado para a sociedade civil: temas éticos e políticos da gestão democrática. São Paulo: Cortez, 2004.

PATEMAN, C. Participação e teoria democrática. Rio de Janeiro: Paz e Terra, 1992.

ROUSSEAU, J.-J. O contrato social: princípios de direito político. Ed. Ridendo Castigat Mores, 2002. Disponível em: <http://www.cfh.ufsc.br/ wfil/contrato. polf $>$ Acesso em: 1 set. 2009.

SCHMITT, C. Verfassungslehre. Trad. A. Caracciolo. Milão: Giuffrè, 1984.

SCHUMPETER, J. A. Capitalismo, socialismo e democracia. Trad. Sérgio Góes de Paula. Rio de Janeiro: Zahar, 1984.

TATAGIBA, L. Os Conselhos Gestores e a democratização das políticas públicas no Brasil. In: DAGNINO, E. (Org.). Sociedade civil e espaços públicos no Brasil. São Paulo: Paz e Terra, 2002, p 47-103.

VÁZQUEZ, A. S. Entre a realidade e a utopia: ensaios sobre política, moral e socialismo. Trad. Gilson B. Soares. Rio de Janeiro: Civilização Brasileira, 2001. 